\title{
DETERMINANTES SOCIOECONÔMICOS DO MICROEMPREENDEDORISMO INDIVIDUAL (MEI): EVIDÊNCIAS E IMPLICAÇÕES
}

Mateus Cerqueira Anício Morais ${ }^{1}$

Magnus Luiz Emmendoerfer ${ }^{2}$

\footnotetext{
${ }^{1}$ Universidade Federal de Viçosa/ PPG ADM/ Departamento de Administração e Contabilidade e Universidade do Estado de Minas Gerais - Campus Carangola

${ }^{2}$ Universidade Federal de Viçosa/ PPG ADM/ Departamento de Administração e Contabilidade
} 


\section{DETERMINANTES SOCIOECONÔMICOS DO MICROEMPREENDEDORISMO INDIVIDUAL (MEI): EVIDÊNCIAS E IMPLICAÇÕES}

Resumo: A busca por entender os determinantes do empreendedorismo tem sido uma atividade presente na literatura especializada desde o inicio do século, a multiplicidade de manifestações da atividade empreendedora, porém, oferece desafios para a convergência de entendimentos sobre suas variáveis explicativas. O presente trabalho visa identificar determinantes socioeconômicos do microempreendedorismo individual (MEI), uma definição originalmente brasileira, contribuindo assim com tais discussões na academia. Para isso, foram analisadas características gerais sobre o MEI brasileiro, bem como uma análise de regressão múltipla incluindo variáveis socioeconômicas dos municípios de Minas Gerais. Os resultados apontam para efeitos significativos de variáveis de educação, renda e saneamento básico sobre a proporção de MEIs no âmbito municipal, seus valores oferecem indícios de que melhores condições socioeconômicas estão inversamente relacionadas ao microempreendedorismo individual, resultado não condizente uma análise aprofundada sobre os empreendedores.

Palavras-Chave: Microempreendedorismo Individual (MEI). Condições Socioeconômicas. Política Pública. Informalidade.

\section{$1 \quad$ Introdução}

O empreendedorismo vem sendo associado a retornos socialmente desejáveis para a economia, pela sua influência sobre o emprego e renda, bem como sobre elementos relacionados a mudanças estruturais de produção (LUNDSTRÖM; STEVENSON, 2006). Tais evidências apontadas pela literatura são refletidas na introdução da temática nas agendas de políticas públicas, e por fim, na adoção de práticas voltadas para o avanço do empreendedorismo em vários países do mundo (AUDRETSCH; GRILO; THURIK, 2007).

Tal contexto influenciou a busca por identificar os determinantes do empreendedorismo de forma a torná-la um desafio cada vez mais presente na literatura acadêmica. Os estudos esforçam-se pela verificação de fatores econômicos, culturais e institucionais significativos para explicar os diferentes níveis de atividade empreendedora entre países, regiões e localidades (APARICIO; URBANO; AUDRETSCH, 2016; CASTAÑO; MÉNDEZ; GALINDO, 2015; FREYTAG; THURIK, 2010; LADO-SESTAYO, 2013).

Ressalta-se, entretanto, que a maioria pesquisas concentram seus olhares sobre um tipo de empreendedorismo, o de elevado crescimento. Tornou-se consenso na literatura que apenas atividades empreendedoras de acelerados retornos econômicos (high growth firms) são pertinentes para a aplicação de recursos públicos (SHANE, 2009). Essa perspectiva predominou, e ainda predomina entre as recomendações de políticas públicas de papers especializados internacionalmente (MORRIS et al., 2016).

Outras abordagens, porém, como as de Morris, Neumeyer e Kuratko (2015) e Morris et al. (2016) ressaltam a importância do fomento público a outras manifestações do empreendedorismo para estruturação de um ecossistema empreendedor. Os autores ressaltam tanto a importância das empresas de elevado crescimento para o vigor e competitividade da
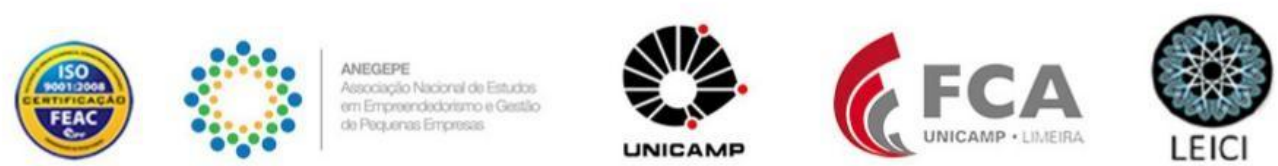
economia, como de empreendimentos de subsistência, sendo estes igualmente importantes por oferecerem uma renda mínima para uma sobrevivência digna de seus proprietários (MORRIS et al., 2016; MORRIS; NEUMEYER; KURATKO, 2015).

O governo brasileiro apresenta historicamente diversas políticas públicas de fomento ao empreendedorismo, que não se restringem a apenas uma forma de manifestações da atividade empreendedora (MORAIS, 2017). Ressalta-se nesse trabalho a Lei Complementar (LC) no 128/2008, que institui a modalidade do Microempreendedorismo Individual (MEI). A nova classificação abrange empreendedores com receita bruta de até sessenta mil reais e que possuem no máximo um funcionário remunerado com um salário mínimo. A Lei 128 reduziu consideravelmente os custos burocráticos e tributários, bem como promoveu incentivos para a contribuição previdenciária dos proprietários de empresas, oferecendo assim condições favoráveis para a abertura e formalização de novos negócios.

Desde sua criação, porém, foram poucos os trabalhos acadêmicos que se dedicaram a estudar os empreendimentos que usufruíram desse marco legal e pouco se sabe sobre seus principais determinantes (BEHLING; LENZI, 2010; CORSEUIL; NERI; ULYSSEA, 2014; LIMA; GONÇALVES; VENDRAMETTO, 2016; MARIA DE OLIVEIRA, 2012; MOREIRA, 2013; SOUZA et al., 2016; VASCONCELOS, 2016).

O presente artigo visa suprir esse gap teórico, tendo por objetivo identificar as possíveis relações entre variáveis sociais e econômicas com a manifestação do microempreendedorismo individual (MEI). Para isso, busca-se primeiramente analisar as características gerais sobre os empreendedores inclusos nessa modalidade em nível nacional, e em seguida identificam-se possíveis determinantes socioeconômicas desse fenômeno.

Acredita-se que tal esforço contribuirá para o entendimento sobre a realidade dos empreendedores atraídos por essa modalidade. Em termos teóricos, este trabalho se insere na discussão sobre as formas de empreendedorismo a serem fomentadas pelos governos, bem como para a identificação de suas variáveis explicativas. Em termos práticos, a apresentação das realidades sociais e econômicas dos empresários beneficiários por essa lei oferece insumos para reflexões fundamentadas, para análises dos efeitos esperados da política pública em questão.

\section{Referencial Teórico}

\section{Empreendedorismo: Conceitos e Tipologias}

São duas as principais correntes de pesquisas que procuram definir o conceito de empreendedorismo. A corrente da "Administração" procura defini-lo como algo que os empreendedores "fazem", ou como aspectos comportamentais manifestados por esses indivíduos. A tentativa de se abrir um novo negócio ou promover a expansão de uma organização existente, por exemplo, é vista por Reynold et al., (1999) como uma ação empreendedora. Wennerkers e Thurik (1999) por sua vez entendem o empreendedorismo como a percepção de novas oportunidades econômicas e a introdução de novas ideias no mercado.

Outros estudos que procuram definir o empreendedorismo, podem ser encontrados na corrente econômica (LUNDSTROM; STEVENSON, 2006). Nessa vertente, os trabalhos definem o empreendedorismo sob uma perspectiva ampla, como um sistema econômico que

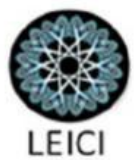


envolve empreendedores, o governo e todo um arranjo legal e institucional favorável à atividade empreendedora (LOWREY, 2003), ou como a relação existente entre o empreendedor e o ambiente ao seu redor (MORRIS, 1996).

$\mathrm{Na}$ presente pesquisa, assume-se o conceito da primeira vertente, definindo o empreendedorismo como a ação de abrir um negócio ou promover a sua expansão. No contexto do microempreendedorismo individual, entende-se que a formalização do empreendimento registra a sua existência, sendo esse um critério de manifestação da atividade empreendedora.

Existem muitos esforços na literatura visando diferenciar e classificar os tipos de empreendedorismo existentes (GEDEON, 2010). A principal forma de diferenciação é dada pelo relatório global "General Entrepreneurship Monitor" (GEM), que tem como parâmetro a motivação para se empreender. Dessa forma os empreendimentos são tipificados em apenas dois grupos: (i) Empreendedorismo por necessidade: quando uma empresa é aberta pela necessidade de subsistência do empreendedor; (ii) Empreendedorismo por Oportunidade: quando o empreendimento surge a partir de uma oportunidade identificada no mercado (MACEDO, 2015).

O empreendedorismo por necessidade tende a ser mais presente em economias menos estáveis, dotadas de elevados graus de desemprego (BLOCK; WAGNER, 2010), isso porque essa forma de empreendedorismo se estabelece como uma saída para crises financeiras passadas pelos indivíduos, em sua maioria são abertos empreendimentos de baixo potencia de crescimento. De maneira geral, países com menores patamares de desenvolvimento tendem apresentar maiores níveis de empreendedorismo por necessidade, enquanto o empreendedorismo por oportunidade se manifesta com maior presença em países com melhores níveis de desenvolvimento (MACEDO, 2015).

Outras formas de empreendedorismo podem ser identificadas no trabalho de Morris, Neumeyer, Kuratko (2015) que distinguem os tipos de empreendedorismo a partir de diversos critérios como porte, volume de produção, capital, nível de crescimento e outras características.

Assim, são determinadas quatro tipologias: (i) Empresas de sobrevivência: que promove a subsistência básica para o empreendedor e sua família, normalmente não possuem instalações e possuem poucos ativos; (ii) Empresas estilo de vida: formada por empreendimentos que proveem um estável retorno para seus proprietários, que de maneira modesta reinvestem em seus negócios, a fim de manter uma competitividade no mercado local; (iii) Empresas de Crescimento Gerenciado: Composto por empresas que possuem um modelo viável de negócio e que buscam um crescimento estável em longo prazo, ocasionalmente produzem novos produtos e expandem seus mercados e suas instalações; (iv) Empresas de elevado (agressivo) crescimento: Conhecidas como gazelas, são empresas de base tecnológica, dotadas de elevada capacidade inovadora e crescimento exponencial (MORRIS; NEUMEYER; KURATKO, 2015).

A respeito dessas classificações, os autores apontam a importância de cada uma delas para a criação de um ecossistema empreendedor saudável, e para atender necessidades específicas da sociedade. Como, por exemplo, o empreendedorismo por sobrevivência que se aproxima da ideia de empreendedorismo por necessidade, pois representa uma saída para muitos indivíduos em momentos de crise. Outras formas de empreendedorismo como "estilo

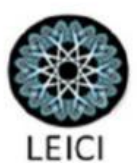


de vida" e "crescimento gerenciado" são importantes para oferecer serviços básicos na sociedade e garantir empregos estáveis no longo prazo. As empresas gazelas são as mais rentáveis e apresentam crescimento acelerado, essas têm sido o foco das políticas públicas de crescimento econômico (MORRIS; NEUMEYER; KURATKO, 2015; SHANE, 2009).

Acredita-se, nesse trabalho, que o microempreendedorismo individual, pelas suas características financeiras (apresentar um rendimento de $\mathrm{R} \$ 60.000$ por ano e no máximo um funcionário pago em salário mínimo), se enquadra entre as tipologias "sobrevivência" e "estilo de vida". A análise a ser apresentada oferece indícios para sustentar essa afirmação, uma vez que, dadas as características dos negócios da categoria MEI e das condições econômicas e sociais que envolvem seus proprietários, é possível deduzir suas motivações e seu enquadramento no mercado.

\section{Determinantes do Empreendedorismo}

Sobre os fatores determinantes do empreendedorismo, Verheul et al. (2002) apontam para uma natureza eclética e interdisciplinar desse fenômeno, que abrange aspectos geográficos, financeiros, administrativos, sociológicos, políticos e outras vertentes. Os autores destacam que são multifatoriais os determinantes do nível de empreendedorismo de uma sociedade.

No mesmo sentido, a OECD (2000) atesta que não existe apenas um único conjunto de causas para determinar o aumento ou o declínio do número de empreendedores em uma sociedade, entretanto, uma série de fatores tecnológicos, econômicos, institucionais e culturais tende a influenciar amplamente a atividade empreendedora entre os indivíduos. Esses trabalhos apontam a relevância de se entender os fatores que podem influenciar a atividade empreendedora no contexto de formulação de políticas públicas de estímulo ao empreendedorismo.

Lundström e Stevenson (2006) apontam que o conhecimento sobre os aspectos que afetam o empreendedorismo na sociedade ainda está sendo construído. De maneira geral, os autores apresentam cinco dimensões, que em interação na sociedade, parecem exercer influencia sobre os níveis de empreendedorismo, são elas: (i) Dimensões estruturais, macroeconômicas e demográficas; (ii) Dimensões Culturais; (iii) Dimensões Pessoais (humanas); (iv) Dimensão da Densidade de PME e da Dinâmica Empreendedora; (v) Dimensão de Políticas Públicas.

No mesmo sentido, o trabalho de Verheul et al. (2001) busca construir uma teoria eclética do empreendedorismo, realizando uma síntese a respeito dos principais fatores determinantes do empreendedorismo. Os autores apontam que, além de serem diversas as formas de empreendedorismo, existem determinantes múltiplos sobre esse fenômeno, por isso, apresentam categorias agregadas de variáveis que explicam o empreendedorismo, como os "Fatores de Oportunidades", que agregam determinantes que oferecem oportunidades para se empreendedor em uma economia, por exemplo, o aumento da renda, a criação de novas tecnologias e outros.

São apresentadas também as categorias "Habilidades de Recursos" e "Preferências e Características", que agregam determinantes do empreendedorismo relacionados aos recursos financeiros e não financeiros benéficos à criação de novos empreendimentos, além das próprias habilidades e características dos indivíduos em uma sociedade. A categoria "Custos e

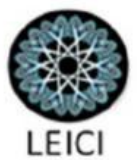


Benefícios" agregam variáveis que influenciam a atratividade para se empreender, políticas de desburocratização, como a LC 128, exercem muita influência sobre esses determinantes (VERHEUL et al., 2001).

A respeito de variáveis explicativas relacionadas às condições sociais e econômicas, como proposto no presente estudo, estão frequentemente distribuídas entre as várias categorias explicativas do empreendedorismo, já apresentadas (LUNDSTRÖM; STEVENSON, 2006; VERHEUL et al., 2001).

A principal medida de estado da economia, o "Produto Interno Bruto" (PIB), é incluso em muitos trabalhos acadêmicos para entender a relação entre o vigor econômico e a atividade empreendedora (PRIEGER et al., 2016; SMITH; CHIMUCHEKA, 2014; URBANO; APARICIO, 2016). A literatura demonstra uma relação em formato de "U" entre o PIB e o empreendedorismo, isso é explicado pelas diversas manifestações desse fenômeno. Empreendimentos motivados por necessidade tendem a se relacionar inversamente às condições econômicas, enquanto por oportunidade, uma relação positiva (LUNDSTRÖM; STEVENSON, 2006).

Variáveis relacionadas à educação são utilizadas em algumas pesquisas como proxy de "Cultura", afim de se entender os efeitos de variáveis culturais sobre os diferentes níveis de empreendedorismo. Castaño, Méndez e Galindo (2015), por exemplo, demonstram o efeito dos anos de estudo sobre o nível de empreendedorismo por oportunidade em diversos países. Os autores apontam que essa variável é mais significativa para explicar a variação da atividade empreendedora em países europeus do que latino-americanos.

Na presente pesquisa, serão inclusas variáveis referentes à saúde e saneamento básico, pouco exploradas na literatura. Entretanto, é possível hipotetizar, por estudos prévios, que a ausência desses elementos em uma sociedade estaria relacionada à condições de baixo desenvolvimento econômico, contexto favorável à informalidade ou empreendedorismo por necessidade (CASTAÑO; MÉNDEZ; GALINDO, 2015; KENYON; KAPAZ, 2005; MACEDO, 2015).

\section{O Perfil do Microempreendedor Individual}

Foi instituída pela Lei Complementar n. ${ }^{\circ}$ 128/2008 uma nova classificação de empreendedorismo, o Microempreendedor Individual, definido como empreendimento, dotado de um faturamento anual de 60 mil reais e que tenha por limite empregatício apenas um colaborador em seu negócio (BRASIL, 2008). A nova medida estabeleceu um novo padrão de contribuição tributária e de seguridade social para os empreendedores brasileiros elegíveis. A criação do MEI instituiu um processo simplificado de obtenção de CNPJ, sem custos, a isenção de tributos federais (IR, PIS, Cofins, IPI e CSLLL) e um novo modelo de contribuição, com uma alíquota fixa de $5 \%$ sobre o salário mínimo para obterem acesso aos benefícios previdenciários.

O Serviço Brasileiro de Apoio à Micro e Pequenas Empresas (SEBRAE) tem produzido relatórios recentes a respeito do perfil do microempreendedor individual (SEBRAE, 2016, 2017). Com base nesses trabalhos serão apresentadas na presente seção informações relevantes para se entender os MEIs brasileiros, tendo por destaque suas principais características geográficas, sociais e econômicas.

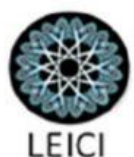


A formalização do Microempreendedorismo Individual teve início no ano de 2009 e desde então apresentou um crescimento médio de 831.237 unidades por ano, até 2016 (SEBRAE, 2017). Em Dezembro de 2017 contabilizaram-se aproximadamente um total de 7.729.234 registros de empreendimentos na modalidade MEI no Brasil (PORTAL DO EMPREENDEDOR, 2017).

Esses números apontam para uma resposta positiva da sociedade a essa política pública, que tem por objetivo principal a formalização de antigos e novos negócios. Em contrapartida, análises acadêmicas oferecem indícios de que os impactos da Lei 128 vão além de suas intenções, uma vez que pode estar sendo utilizada como um instrumento de terceirização dos quadros de funcionários de empreendimentos estabelecidos ou de redução do tamanho de empresas (CORSEUIL; NERI; ULYSSEA, 2014).

Em termos regionais, um relevante número de MEIs se concentra na Região Sul, Sudeste e no estado da Bahia, no Nordeste. São Paulo é o estado mais expressivo em número de microempreendedores individuais (1.711.010), o Rio de Janeiro está em segundo (816.607) e Minas Gerais em terceiro (729.746), colocando a região sudeste como a mais empreendedora no que se refere a essa modalidade de empreendedorismo no país.

O relatório do Sebrae (2017) sobre o MEI indica, também, que o microempreendedorismo individual apresenta maior concentração em grandes centros urbanos, como as capitais. A distribuição geográfica do microempreendedorismo individual indica a possibilidade desse modelo de empreendedorismo estar ligado a um maior dinamismo econômico, por esses empreendimentos se concentrarem em regiões com essa característica. Essa hipótese, porém, deve ser sustentada por outros argumentos.

Em termos demográficos, tendo por referência o ano de 2016, os microempreendedores individuais são em sua maioria do sexo masculino, $52,4 \%$ da população de MEIs, sendo, portanto, 47,6\% do sexo feminino. As estatísticas mostram também que $43 \%$ dos MEIs são brancos, $42 \%$ pardos, $11 \%$ pretos, $2 \%$ oriental e $1 \%$ indígenas. Esses números acompanham as proporções raciais da população brasileira em geral, indicadas no censo de 2010 (IBGE, 2011).

$\mathrm{Na}$ economia, os setores com maior número de microempreendedores individuais são os de comércio e serviço, sendo as atividades mais frequentes aquelas relacionadas ao comércio varejista, serviços de alimentação e de beleza, práticas de baixo potencial para o crescimento acelerado. Essa característica distancia essa modalidade de empreendedorismo das manifestações mais contempladas por políticas públicas em nível internacional, e do interesse do mainstream da pesquisa científica, que tendem a empenhar esforços de estudo e fomento em empreendimentos de bases tecnológicas (MORRIS; NEUMEYER; KURATKO, 2015). Além disso, sustenta o argumento de que a política do MEI tem alcançado empreendimentos próximos das categorias "sobrevivência" ou "estilo de vida" apresentada por Morris, Neumeyer e Kuratko (2015).

Por fim, cabe mencionar o perfil socioeconômico dos microempreendedores individuas que podem ser parcialmente observados pela identificação do nível educacional e de renda dos empreendedores em análise. Segundo o relatório a respeito do perfil dos MEIs (SEBRAE, 2017), a maioria dos empresários individuais possui o ensino médio completo (32\%) ou ensino superior completo (20\%) indicando que mais da metade da população de MEIs possuem pelo menos 12 anos de estudo cursados. Um indicador favorável, no que refere

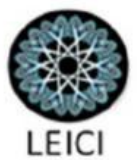


à alfabetização e domínio de técnicas básicas para a prática da gestão. Além disso, apenas $1 \%$ dos MEIs estudados não possui instrução escolar, como indica o relatório.

A respeito do nível de renda dos microempreendedores individuais, Sebrae (2017) oferece informações relevantes para seu entendimento. O relatório disponibiliza informações sobre a distribuição dos MEIs em casses sociais, e demonstra que grande parte dos indivíduos que abrem uma empresa nessa modalidade, possui boas condições financeiras. A figura 1, criada com base nos dados fornecidos, representa esse panorama.

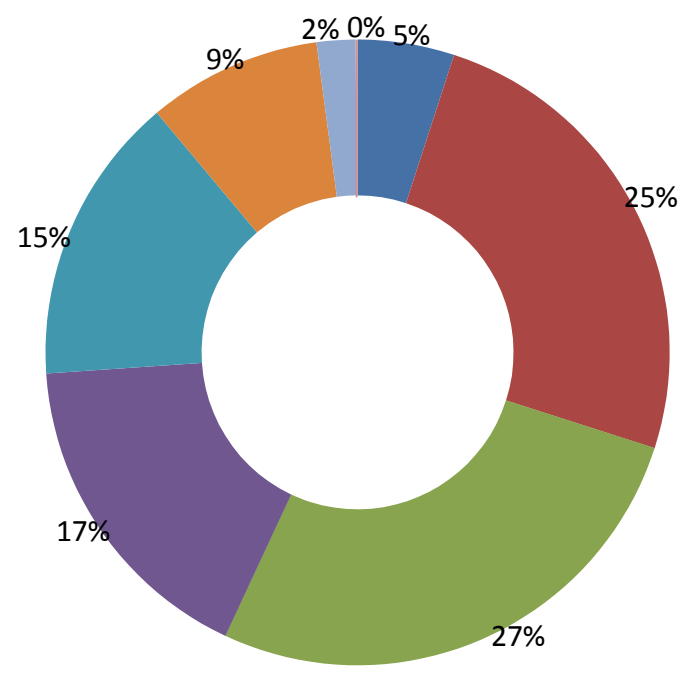

- Alta Classe alta (acima de R\$ $3.515,01)$

Baixa Classe alta $(\mathrm{R} \$ 1.444,01$ $\mathrm{R} \$ 3.515,00$ )

Alta Classe Média (R\$ 908,01 - R\$ $1.444,00)$

Média Classe Média (R\$625,01 $\mathrm{R} \$ 908,00$ )

Baixa Classe Média (R\$ 412,01 $R \$ 625,00)$

- Vulneráveis (R\$230,01 - R\$ 412,00)

Pobre (R\$ 115,01-R\$ 230,00)

Extremamente Pobre (abaixo de $\mathrm{R} \$ 115,00)$

Figura 1. Proporção de MEI por classe sócio econômica

Fonte: Elaborado pelo autor. Nota: Dados provenientes de Sebrae (2017), valores referentes à renda familiar per capita.

A partir da ilustração é possível perceber que 57\% dos microempreendedores individuais apresentam renda familiar per capita acima de $\mathrm{R} \$ 908,01$, portanto, em sua maioria, os MEIs se enquadram em classes sociais entre "classe média alta" (R\$908,01$\mathrm{R} \$ 1444,01)$ e "alta classe alta" (acima de $\mathrm{R} \$ 3.515,01)$. São relativamente poucos os microempreendedores das classes menos favorecidas (11\%), o que pode estar relacionado à dois fatores: (i) indivíduos que abriram suas empresas podem ter melhorado sua condição econômica ao logo dos anos, ascendendo socialmente; (ii) empreendedores autônomos pertencentes à classes menos favorecidas tem optado pela informalidade. Questões a serem respondidas por futuras pesquisas.

As informações descritas nessa seção demonstram que o microempreendedorismo individual se manifesta com maior intensidade em regiões dotadas de maior dinamismo econômico, representadas pelas concentrações de MEIs nas regiões sul e sudeste, bem como em grandes aglomerações urbanas. Além disso, é possível perceber que esse modelo de empreendedorismo é mais presente entre grupos com melhores rendas e dotados de uma considerável educação formal.

A análise do perfil do microempreendedorismo individual indica uma relação positiva entre esse fenômeno e melhores condições de vida, questão central da presente pesquisa. Cabe 
entender, também, se esses elementos são confirmados a partir de uma análise "macro", sob indicadores municipais, o que demonstraria se a população do Microempreendedorismo Individual representar as condições da localidade em que está presente, ou, caso contrário, se essa modalidade de empreendedorismo tem garantido melhores condições de vida para aqueles que a assumem como ocupação no mercado.

\section{Abordagem Metodológica}

O artigo proposto tem por objetivo identificar a possível relação existente entre condições sociais e econômicas e o microempreendedorismo individual (MEI) manifestado no âmbito municipal brasileiro. Para isso, optou-se por realizar uma análise de regressão linear, que consiste em um modelo estatístico aplicado para prever o comportamento de uma variável quantitativa dependente, a partir de sua relação com uma ou mais variáveis explicativas (PESTANA; GAGEIRO, 2008). Tendo por base as relações existentes entre variáveis (dependente e explicativas) essa análise fornece uma função para identificar a melhor associação entre as mesmas.

Por se tratar de um modelo composto por mais de uma variável exógena será desenvolvida uma análise de regressão múltipla, a qual requer, como medidas primárias, que as variáveis inclusas no modelo sejam escalares e que a relação entre elas seja linear e aditiva (PESTANA; GAJEIRO, 2005). A função de regressão é estimada por Mínimos Quadrados Ordinários (MQO) a qual fornece uma função estimada a partir da soma dos desvios dos evrros elevada ao quadrado (CLEFF, 2011).

Esse modelo (regressão linear múltipla) é amplamente utilizado em pesquisas relacionadas ao empreendedorismo que frequentemente visam identificar os determinantes desse fenômeno (APARICIO; URBANO; AUDRETSCH, 2016; CASTAÑO; MÉNDEZ; GALINDO, 2015; GIACOMIN et al., 2011; JIMÉNEZ et al., 2015; LADO-SESTAYO,

2013; MELO; SAMPAIO; OLIVEIRA, 2015), ou medir os impactos dos diversos tipos de empreendedorismo sobre variáveis econômicas (BARROS; PEREIRA; MARIA, 2008; FONTENELE, 2010), bem como as relações entre o empreendedorismo e variáveis sociais e individuais (BLOCK; WAGNER, 2010; JULIÃO, 2014), próximo ao que é proposto nesse trabalho.

Sob a luz da teoria e tendo em vista a proposta de pesquisa foram coletados dados transversais, provenientes dos 853 municípios do estado de Minas Gerais para o ano de 2013. Justifica-se esse ano pela indisponibilidade de dados de anos posteriores para todas as variáveis de análise. A função estimada pode ser representada da seguinte forma:

Sendo:

$\mathrm{i}=1,2,3,4, \ldots, \mathrm{n}$

$\alpha=$ intercepto, sendo o valor médio de $\mathrm{Y}$ quando $\mathrm{X}$ é igual à zero

$\beta=$ Coeficiente de relação da variável explicativa

MEI = Variável dependente relativa ao Microempreendedorismo Individual (MEI);

Educ $=$ Variáveis indicadas pela teoria relacionadas à educação
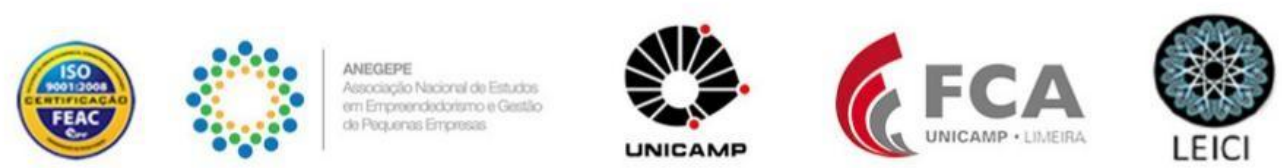
Sáude $=$ Variáveis indicadas pela teoria relacionadas à saúde

Sani $=$ Variáveis indicadas pela teoria relacionadas à saneamento

Rend $=$ Variáveis indicadas pela teoria relacionadas à renda

$\varepsilon=$ Variável aleatória residual, descreve os efeitos da variável endógena não explicados pelas variáveis endógenas

A delimitação para Minas Gerais se deu pela possibilidade de abranger uma amostra satisfatória a partir do estado com maior número de municípios do Brasil, sendo o terceiro maior em número de Microempreendedores Individuais (MEI) no país e, portanto, um caso propício para se entender a relação esse fenômeno e as condições sociais dos municípios.

As variáveis inclusas no modelo estão explicitadas do Quadro 1.

Quadro 1: Descrição de variáveis e fonte dos dados da pesquisa.

\begin{tabular}{|c|c|c|}
\hline Variável & Descrição & Fonte \\
\hline propMEI & $\begin{array}{l}\text { Proporção de Microempreendedores individuais sobre o } \\
\text { número de pessoas ocupadas. }\end{array}$ & FIRJAN \\
\hline Pibpcap & Produto Interno Bruto per capita municipal (mil) & IBGE \\
\hline Proplixo & $\begin{array}{l}\text { Proporção de famílias atendidas pela Estratégia de Saúde } \\
\text { da Família, antigo psf, atendida com serviço público de } \\
\text { coleta seletiva }\end{array}$ & DATASUS/SUS \\
\hline Propesgo & $\begin{array}{l}\text { Proporção de famílias atendidas pela Estratégia de Saúde } \\
\text { da Família, antigo psf, atendida com serviço de esgoto } \\
\text { para captação de fezes e urina }\end{array}$ & DATASUS/SUS \\
\hline Propagua & $\begin{array}{l}\text { Proporção de famílias atendidas pela Estratégia de } \\
\text { Saúde da Família, antigo psf, cujo tratamento de água é } \\
\text { dado pela filtragem da água recebida }\end{array}$ & DATASUS/SUS \\
\hline Propenerg & $\begin{array}{l}\text { Proporção de famílias atendidas pela Estratégia de Saúde } \\
\text { da Família, antigo psf, que são atendidas com serviço de } \\
\text { energia elétrica. }\end{array}$ & DATASUS/SUS \\
\hline Propimun & $\begin{array}{l}\text { Proporção de doses de vacinas aplicadas por famílias } \\
\text { atendidas pela Estratégia de Saúde da Família, antigo } \\
\text { psf. }\end{array}$ & DATASUS/SUS \\
\hline Propobt & $\begin{array}{l}\text { Proporção de óbitos, registrados por local de residência, } \\
\text { que poderiam ser evitadas por atendimentos da atenção } \\
\text { básica para população entre } 5 \text { e } 74 \text { anos de idade, por } \\
\text { famílias atendidas pela Estatégia de Saúde da Famíla, } \\
\text { antigo psf. }\end{array}$ & DATASUS/SUS \\
\hline Proptrabfund & $\begin{array}{l}\text { Razão do número de trabalhadores com ensino } \\
\text { fundamental sobre o total de vínculos totais de trabalho } \\
\text { registrados no Ministério de Trabalho, emprego e } \\
\text { previdência social. }\end{array}$ & $\begin{array}{l}\text { RAIS/CAGED - } \\
\text { MTE }\end{array}$ \\
\hline Proptrabmed & $\begin{array}{l}\text { Razão do número de trabalhadores com ensino médio } \\
\text { sobre o total de vínculos totais de trabalho registrados no } \\
\text { Ministério de Trabalho, emprego e previdência social. }\end{array}$ & $\begin{array}{l}\text { RAIS/CAGED - } \\
\text { MTE }\end{array}$ \\
\hline Proptrabsup & $\begin{array}{l}\text { Razão do número de trabalhadores com ensino superior } \\
\text { sobre o total de vínculos totais de trabalho registrados no }\end{array}$ & $\begin{array}{l}\text { RAIS/CAGED - } \\
\text { MTE }\end{array}$ \\
\hline
\end{tabular}


Ministério de Trabalho, emprego e previdência social.

\begin{tabular}{|c|c|c|}
\hline Alfund & $\begin{array}{l}\text { Razão do número de alunos matriculados no ensino } \\
\text { fundamental pelo número de turmas disponíveis para o } \\
\text { ensino fundamental multiplicado por } 100\end{array}$ & $\begin{array}{c}\text { EDUCACENSO/IN } \\
\text { EP/MEC }\end{array}$ \\
\hline Almed & $\begin{array}{l}\text { Razão do número de alunos matriculados no ensino } \\
\text { médio pelo número de turmas disponíveis para o ensino } \\
\text { médio multiplicado por } 100\end{array}$ & $\begin{array}{c}\text { EDUCACENSO/IN } \\
\text { EP/MEC }\end{array}$ \\
\hline Distfund & $\begin{array}{l}\text { Razão do número de alunos matriculados no ensino } \\
\text { fundamental com idade superior à idade regular da série } \\
\text { pelo número total de alunos matriculados no ensino } \\
\text { fundamental multiplicado por } 100\end{array}$ & $\begin{array}{c}\text { EDUCACENSO/IN } \\
\text { EP/MEC }\end{array}$ \\
\hline Distmed & $\begin{array}{l}\text { Razão do número de alunos matriculados no ensino } \\
\text { médio com idade superior à idade regular da série pelo } \\
\text { número total de alunos matriculados no ensino médio } \\
\text { multiplicado por } 100\end{array}$ & $\begin{array}{c}\text { EDUCACENSO/IN } \\
\text { EP/MEC }\end{array}$ \\
\hline
\end{tabular}

Fonte: Elaborado pelos autores

As variáveis foram relativizadas para serem equiparadas na regressão. Realizou-se uma análise exploratória de dados, aonde foi possível identificar medidas de posição e distribuição dos dados, sendo analisada a normalidade dos mesmos, bem como evidenciados e retirados os outliers com distâncias consideráveis.

Além dos pressupostos inerentes a um modelo de regressão linear múltipla, como a homocedasticidade, ausência de autocorrelação e de multicolinearidade (BRUNI, 2009), a validade do modelo é testada pelo Teste f, o qual testa a hipótese (H0) da nulidade dos coeficientes do parâmetro das variáveis independentes inclusas no modelo (TRIOLA, 2005).

A partir desse procedimento testa-se também a significância dos coeficientes de cada variável explicativa por Teste t. A capacidade explicativa do modelo é dada por que oferece o percentual da variação da variável dependente, explicada pelas variáveis exógenas. A homocedasticidade pode é testada pela da análise da dispersão dos valores dos resíduos estandardizados e a autocorrelação residual pelo teste de Dubin-Watson (TRIOLA, 2005).

\section{$5 \quad$ Resultados}

Tendo realizado os procedimentos metodológicos previamente descritos, foi possível obter resultados que demonstram a relação existente entre o microempreendedorismo individual e as condições sociais entre municípios mineiros. Na Tabela 1 são apresentadas as estatísticas descritivas, fruto da realização da análise exploratória dos dados de pesquisa.

Tabela 1. Estatísticas Descritivas

\begin{tabular}{cccccc}
\hline Variáveis & Obs & Média & Desv. Padrão & Min & Max \\
\hline propMEI & 596 & 0,113 & 0,095 & 0,013 & 1,989 \\
Pibpcap & 596 & 12,480 & 7,140 & 0,954 & 80,729 \\
Proplixo & 584 & 0,749 & 0,186 & 0,188 & 1,000 \\
propesgo & 584 & 0,631 & 0,286 & 0,000 & 1,000 \\
propagua & 584 & 0,826 & 0,156 & 0,830 & 1,000 \\
\hline
\end{tabular}




\begin{tabular}{cccccc}
\hline propenerg & 584 & 0,982 & 0,020 & 0,420 & 1,011 \\
propimun & 584 & 1,034 & 0,316 & 0,000 & 2,891 \\
Propobt & 584 & 0,004 & 0,001 & 0,015 & 0,016 \\
proptrabfund & 573 & 0,128 & 0,044 & 0,085 & 0,297 \\
proptrabmed & 573 & 0,358 & 0,086 & 0,031 & 0,610 \\
proptrabsup & 573 & 0,131 & 0,049 & 0,284 & 4,100 \\
Alfun & 596 & 20,87 & 3,092 & 12,30 & 28,500 \\
Almed & 595 & 29,70 & 4,659 & 4,100 & 41,400 \\
Disfund & 596 & 17,40 & 5,850 & 7,400 & 39,100 \\
Dismed & 595 & 28,00 & 8,744 & 0,013 & 58,800 \\
\hline
\end{tabular}

Fonte: Elaborado pelo autor

Foram excluídos alguns casos devido aos outliers, identificados no BoxPlot, com elevada discrepância da distribuição dos dados em geral. Optou-se por não excluir todos (ex. com distância moderada), a fim de que seja mantido o máximo de casos possível, sendo aceitável até o ponto em haja distribuições quase simétricas e próximas de mesocúrticas (PESTANA; GAGEIRO, 2008). A relativização das variáveis pode ser evidenciada também tabela 1 o que garante que possam sem comparáveis entre si e inclusas no modelo. Ressalta-se que a proporção de MEIs supera o valor de cem por cento devido a um maior número de registro de microempreendedores frente ao da população ocupada em alguns municípios.

\section{Análise e Discussão}

A respeito do modelo gerado, apresentou um Teste $\mathrm{F}$ significativo, sendo validado, indicando que pelo menos uma das variáveis explicativas possui relação significativa com a variável dependente na regressão. Seu poder explicativo, porém, não se mostra satisfatório, por apresentar um $=0,138$, apontando que apenas $13,8 \%$ da variação da proporção de microempreendedores individuais nos municípios mineiros pode ser explicada por mudanças nas variáveis inclusas nesse modelo. Isso se dá pela existência de múltiplos determinantes do empreendedorismo, como mencionado no referencial teórico. Essa circunstância, porém não inviabiliza a realização dessa pesquisa. A tabela 2 apresenta esses resultados.

Tabela 2. Efeitos de variáveis sociais e econômicas sobre o microempreendedorismo individual (MEI).

\begin{tabular}{cl}
\hline Variável & propMEI \\
\hline Pibpcap & $-0,356(0,000)^{* * *}$ \\
Proplixo & $0,061(0,333)$ \\
Propesgo & $0,040(0,447)$ \\
Propagua & $0,071(0,090)^{*}$ \\
Propenerg & $-0,011(0,806)$ \\
Propimun & $-0,007(0,883)$ \\
Propobt & $0,012(0,809)$ \\
Proptrabfund & $0,018(0,671)$
\end{tabular}




\begin{tabular}{cc} 
Proptrabmed & $-0,026(0,539)$ \\
Proptrabsup & $-0,011(0,792)$ \\
Alfund & $0,118(0,023) * *$ \\
Almed & $-0,008(0,851)$ \\
Distfund & $0,143(0,004) * * *$ \\
Distmed & $-0,038(0,445)$ \\
\hline Const. & $0,083(0,476)$ \\
\hline$=0,138$ & Teste F $=0,000$ \\
Durbin-Watson $=1,944$ & Excluidas: aprovfund; aprovmed
\end{tabular}

Fonte: Elaborado pelos autores. Nota: (***) nível de significância à 1\%, (**) nível de significância à 5\%. (*) nível de significância à 10\%. Estimativas com erros padrões robustos. Erro padrão correspondente entre parênteses.

O teste de autocorrelação, Durbin -Watson, analisa a independência entre as variáveis aleatórias residuais. Sendo ele de 1,944 e estando entre 1,36 e 2,64, aceita-se a hipótese de que a covariância entre os resíduos é nula, ou seja, ausência de autocorrelação. Por fim, ressalta-se a exclusão de duas variáveis no modelo, o "número de aprovados no ensino fundamental e médio" (aprovfund, aprovmed), acusados por multicolinearidade, o que violaria um dos pressupostos da análise por regressão linear (independência entre as variáveis explicativas).

No modelo é possível perceber que existem quatro coeficientes significativos, um relacionado a uma variável econômica, o "PIB per capita", um relacionado a uma variável de saneamento básico, "proporção de famílias atendidas pelo psfs, que possuem água filtrada" e dois coeficientes significativos relacionados à educação, estando, portanto, as variáveis de saúde e de trabalho não significativas no modelo.

Como era de se esperar, o PIB per capita é a variável mais significativa e com maior peso de explicação sobre o microempreendedorismo individual. Segundo os resultados, a cada uma unidade de variação da renda per capita de um município, diminui-se a proporção de microempreendedores individuais entre a população ocupada em 0,365. Isso indica uma relação inversa entre essas duas variáveis, ou seja, municípios com maior renda tendem a apresentar menores proporções de microempreendedorismo individual. Tendo em vista a literatura acadêmica, o resultado aproxima o microempreendedorismo individual às característica manifestadas pelo empreendedorismo por necessidade, por ser mais presente em regiões com menores renda per capita (ÁCS; AUTIO; SZERB, 2014; CASTAÑO; MÉNDEZ; GALINDO, 2015).

Tal evidência, entretanto, quando contrastada com os resultados apresentados pelo relatório do perfil do MEI (SEBRAE, 2017), previamente discutido nesse trabalho, reforça a ideia de que, mesmo o modelo indicando que MEIs tendem a estar mais presente em municípios com menores proporções de renda, a maioria dos microempreendedores individuais contrastam com essa realidade ao comporem classes sociais mais elevadas. Esse resultado pode ser um indício de que empreendedores autônomos elegíveis ao MEI são bem sucedidos em seus retornos financeiros. 
Outro ponto a ser destacado desse resultado, é a possibilidade de que melhores condições econômicas tendem a gerar empreendimentos de maiores portes, isso por ser possível se formar negócios sustentáveis em cenários de melhores patamares de renda. Por fim, uma análise sobre a relação entre microempreendedorismo individual e informalidade pode ser feita. Ao contrário do que apontam alguns trabalhos, como o de Corseuil, Neri e Ulyssea (2014), melhores condições econômicas podem não incentivar a formalização de negócios através da política do MEI.

Os coeficientes significativos relacionados à educação foram os que mais se destacaram em termos de quantidade, frente aos outros conjuntos de variáveis. Segundo Fontes e Pero (2011) a educação é um bom indicador de renda entre os microempreendedores, pois tende a afetar positivamente os retornos e a gestão dos negócios. Destaca-se no modelo gerado o efeito do ensino fundamental sobre o microempreendedorismo individual.

$\mathrm{O}$ aumento de alunos por turma no ensino fundamental e de distorções em sua conclusão (indicadores da má qualidade do ensino) tende a afetar positivamente o número de MEIs nos municípios. Ou seja, possivelmente, a má qualidade da educação fundamental está relacionada a uma maior proporção de microempreendedores individuais em um município. Esse resultado converge elementos apontados no relatório Sebrae (2017), o qual apresenta a porcentagem de MEIs com ensino fundamental incompleto como a terceira maior (16\%) entre outros níveis de escolaridade.

Por fim, tem-se por significativo o coeficiente da variável "Propagua", que indica a proporção de famílias atendidas pela ESF, cujo tratamento de água é dado pela filtragem da água, um indicador de saneamento básico. Segundo os resultados do modelo, um aumento de uma unidade na variável explicativa, tende a aumentar a proporção de MEIs em 0,071 unidades. A variação dessa variável entre os municípios analisados apresenta baixa amplitude, entretanto, os resultados encontrados acompanham a evidência de que são poucos os microempreendedores pertencentes a classes de maior vulnerabilidade social.

\section{Considerações Finais}

O microempreendedorismo individual tem crescido nos últimos anos, indícios de sucesso da criação da LC 128, cujo objetivo é incentivar a formalização de empreendimentos novos ou previamente existentes na economia informal. A presente pesquisa buscou identificar os determinantes sociais e econômicos dessa modalidade de empreendedorismo, contribuindo assim, para a literatura acadêmica, que apresenta poucos esforços para entender esse fenômeno, bem como os determinantes aqui propostos.

A apresentação dos setores e atividades econômicas mais frequentes entre os MEIs demonstra que esse tipo de empreendimento se relaciona com produtos e serviços de menor valor agregado o que oferece baixo potencial de crescimento dessas empresas. Em consonância à literatura, foi possível deduzir que o microempreendedorismo individual se aproxima do empreendedorismo por necessidade, além de outras categorias como "por sobrevivência" e "estilo de vida", podendo ser vistos como importantes instrumentos de fuga de situações de crise econômica, ou para a promoção de empregos e bens e serviços básicos na sociedade.

Os resultados encontrados apontam que, de maneira geral, podem existir diferenças entre condições sociais e econômicas dos microempreendedores analisados e dos municípios

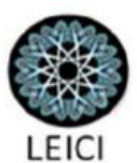


que de onde proveem. Uma vez que a maioria dos MEIs brasileiros apresentam maiores níveis de renda e de escolaridade, enquanto o modelo gerado para os municípios indicam uma possível relação inversa entre a proporção de microempreendedores individuais e as variáveis de condições sociais.

Enquanto a maioria dos microempreendedores individuais pertence a classes sociais mais elevadas, e maiores níveis de educação, a relação inversa dessas variáveis para o municípios podem demonstrar duas circunstancias distintas: (i) empreendedores autônomos com menores condições de vida tem se mantido na informalidade; ou (ii) microempreendedores individuais beneficiados pela política tem conseguido ascender socialmente, atingindo melhores patamares de renda, educação e saneamento. Questões a serem respondidas por futuras pesquisas.

\section{$8 \quad$ Referências Bibliográficas}

ÁCS, Zoltán J.; AUTIO, Erkko; SZERB, László. National Systems of Entrepreneurship: Measurement issues and policy implications. Research Policy, v. 43, n. 3, p. 476-494, 2014.

APARICIO, Sebastian; URBANO, David; AUDRETSCH, David. Institutional factors, opportunity entrepreneurship and economic growth: Panel data evidence. Technological Forecasting and Social Change, v. 102, p. 45-61, 2016.

AUDRETSCH, David B; GRILO, Isabel; THURIK, A Roy. Explaining entrepreneurship and the role of policy: A framework. Handbook of research on entrepreneurship policy, p. 1-17, 2007.

BARROS, Aluízio Antonio De; PEREIRA, Miranda de Araújo; MARIA, Cláudia. Empreendedorismo e crescimento econômico : uma análise empírica. Revista de Administração Contemporânea, v. 12, n. 4, p. 975-993, 2008.

BEHLING, Gustavo; LENZI, Fernando César. Você É Mei? Porque? Uma Análise Dos Influenciadores Da Decisão De Formalização De Microempreendedores Individuais (Mei). Mangueira, n. 2010, p. 1-15, 2010.

BLOCK, Joern H.; WAGNER, Marcus. Necessity and Opportunity Entrepreneurship : characteristics and earnings differentials. SBR, n. April, p. 154-174, 2010.

BRASIL. LEI COMPLEMENTAR N $N^{\circ}$ 128, DE 19 DE DEZEMBRO DE 2008. Disponível em: <http://www.planalto.gov.br/ccivil_03/leis/LCP/Lcp128.htm>. Acesso em: 25 dez. 2017.

CASTAÑO, María-Soledad; MÉNDEZ, María-Teresa; GALINDO, Miguel-Ángel. The effect of social, cultural, and economic factors on entrepreneurship. Journal of Business Research, v. 68 , n. 7, p. 1496-1500, 2015.

CORSEUIL, Carlos Henrique; NERI, Marcelo Côrtes; ULYSSEA, Gabriel. Uma Análise Exploratória Dos Efeitos Da Política De Formalização Dos Microempreendedores Individuais. , Texto para Discussão., $\mathrm{n}^{\text {o }}$ 1939. Rio de Janeiro: [s.n.], 2014. Disponível em: <http://hdl.handle.net/10419/121626>. Acesso em: 11 jun. 2017.

FONTENELE, Raimundo Eduardo Silveira. Empreendedorismo, Competitividade e Crescimento Econômico : Evidências Empíricas Entrepreneurship, Competitiveness and 
Economic Growth : Empirical Evidence. Revista de Administração Contemporânea, v. 14, n. 6, p. 1094-1112, 2010.

FONTES, Adriana; PERO, Valéria. Desempenho dos Microempreendedores no Brasil. Revista Economia, v. 12, p. 635-665, 2011..

FREYTAG, Andreas; THURIK, Roy. Entrepreneurship and its determinants in a crosscountry setting. Entrepreneurship and Culture, p. 157-170, 2010.

GEDEON, Steve. What Is Entrepreneurship? Entrepreneurial Practice Review, v. 1, n. 3, p. 16-35, 2010.

GIACOMIN, Olivier et al. Opportunity and/or necessity entrepreneurship? The impact of the socio-economic characteristics of entrepreneurs. MPRA: Munich Personal RePEc Archive, $\mathrm{n}^{\circ}$ 29506. Munich: [s.n.], 2011.

IBGE. Censo Demográfico 2010. . Rio de Janeiro, RJ - Brasil: [s.n.], 2011. Disponível em: $<$ https://biblioteca.ibge.gov.br/visualizacao/periodicos/93/cd_2010_caracteristicas_populacao _domicilios.pdf>. Acesso em: 24 dez. 2017.

JIMÉNEZ, Alfredo et al. The impact of educational levels on formal and informal entrepreneurship. BRQ Business Research Quarterly, v. 18, n. 3, p. 204-212, 2015.

JULIÃO, Flávio. Fatores Determinantes da Satisfação de Usuários do Programa Microempreendedor Individual Determinants of the Satisfaction of the Brazilian Individual Micro-entrepreneur Program. TPA - Teoria e Prática em Administração, v. 4, n. 1, p. 156$179,2014$.

KENYON, Thomas; KAPAZ, Emerson. The Informality Trap: Tax Evasion, Finace, and Productivity in Brazil. , Public Policy for the Private Sector., n ${ }^{\circ}$ 301. [S.1: s.n.], 2005.

LADO-SESTAYO, Rubén. Macro Determinants of Entrepreneurship : Location's role. Smart Regions for a Smarter Growth Strategy, 2013.

LIMA, Kelly; GONÇALVES, Fonseca; VENDRAMETTO, Oduvaldo. Microempreendedor Individual: Alternativa Para Emprego E Renda Microenterprise Individual: Alternative Employment And Income. 2016, Salvador: COPEC, 2016. p. 91-95.

LUNDSTRÖM, A.; STEVENSON, L. A. Entrepreneurship policy: theory and practice. New York/Boston/Dordrecht/London/Moscow: Kluwer Academic Publishers, 2006.

MACEDO, Mariano de Matos [et. al.]. Empreendedorismo no Brasil 2015. . [S.l: s.n.], 2015.

MARIA DE OLIVEIRA, João. Empreendedor Individual: ampliação da base formal ou substituição do emprego? , Repositório do Conhecimento IPEA. [S.l: s.n.], 2012.

MELO, Felipe Luiz Bezerra; SAMPAIO, Luciano Menezes Bezerra; OLIVEIRA, Renato Lima De. Corrupção Burocrática e Empreendedorismo : Uma Análise Empírica dos Estados Brasileiros. RAC - Revista de Administração Contemporânea, v. 19, n. 3, p. 374-397, 2015.

MORAIS, Mateus Cerqueira Anício. Políticas públicas de fomento ao empreendedorismo no âmbito municipal brasileiro : o caso de belo horizonte - $m g$. 2017. $139 \mathrm{f}$. Universidade Federal de Viçosa, 2017. 
MOREIRA, RFC. Empreendedorismo e Inclusão Produtiva: uma análise de perfil do microempreendedor individual beneficiário do Programa Bolsa Família. Radar: tecnologia, produção e comércio exterior. [S.l: s.n.], 2013. Disponível em:

<http://repositorio.ipea.gov.br/bitstream/11058/5648/1/Radar_n25_Empreendedorismo.pdf >. Acesso em: 29 maio 2017.

MORRIS, Michael H. et al. Distinguishing Types of Entrepreneurial Ventures: An IdentityBased Perspective. Journal of Small Business Management, v. 0, n. 0, p. 1-22, 2016.

MORRIS, Michael H.; NEUMEYER, Xaver; KURATKO, Donald F. A portfolio perspective on entrepreneurship and economic development. Small Business Economics, v. 45, n. 4, p. 713-728, 2015.

PORTAL DO EMPREENDEDOR. Estatísticas - Portal do Empreendedor - MEI.

Disponível em: <http://www.portaldoempreendedor.gov.br/estatisticas〉. Acesso em: 24 dez. 2017.

PRIEGER, James E. et al. Economic Growth and the Optimal Level of Entrepreneurship. World Development. [S.l: s.n.]. , 2016

SEBRAE. Perfil do Microempreendedor Individual 2015. . Brasília/DF: [s.n.], 2016. Disponível em: <http://datasebrae.com.br/wp-content/uploads/2017/03/Perfil-doMicroempreendedor-Individual-2015-Final.pdf>. Acesso em: 24 dez. 2017.

SEBRAE. Perfil do Microempreendedor Individual 2017. . Brasília/DF: [s.n.], 2017. Disponível em: 〈www.sebrae.com.br〉. Acesso em: 24 dez. 2017.

SHANE, Scott. Why encouraging more people to become entrepreneurs is bad public policy. Small Business Economics, v. 33, n. 2, p. 141-149, 2009.

SMITH, Wilhelmina; CHIMUCHEKA, Tendai. Entrepreneurship, Economic Growth and Entrepreneurship Theories. Mediterranean Journal of Social Sciences, 2014.

SOUZA, Donizeti Leandro De et al. Empreendedorismo e desenvolvimento local: uma análise do programa Microempreendedor Individual em Minas Gerais, Brasil.

Desenvolvimento em Questão, v. 14, n. 37, p. 262, 30 nov. 2016.

URBANO, David; APARICIO, Sebastian. Entrepreneurship capital types and economic growth: International evidence. Technological Forecasting and Social Change, v. 102, 2016.

VASCONCELOS, KELLY SAMÁ LOPES DE. De empresário individual formal a microempreendedor individual (MEI): Uma análise dos benefícios da política de formalização. 2016. 1-64 f. Universidade Federal de Pernambuco, CAA, Programa de PósGraduação em Economia, 2016.

VERHEUL, Ingrid et al. An Eclectic Theory of Entrepreneurship. Erasmus, p. 48, 2001. 